REVISTA DE ESTUDOS EM ARTES CÊNICAS

E-ISSN 2358.6958

\title{
Performance é Corpo, a Crise é do Corpo: Entrevistas com professores do ensino emergencial remoto
}

\author{
Estela Vale Villegas
}

\section{Para citar este artigo:}

VILLEGAS, Estela Vale. Performance é Corpo, a Crise é do Corpo: Entrevistas com professores do ensino emergencial remoto. Urdimento - Revista de Estudos em Artes Cênicas, Florianópolis, v. 3, n. 42, dez. 2021.

do) DOI: http:/dx.doi.org/10.5965/1414573103422021e0112

do)

Este artigo passou pelo Plagiarism Detection Software| iThenticate 
Performance é Corpo, a Crise é do Corpo:

Entrevistas com professores do ensino emergencial remoto ${ }^{1}$

Estela Vale Villegas ${ }^{2}$

\begin{abstract}
Resumo
Depois de um longo estudo sobre a abordagem da performance na educação, a pandemia coloca em questão não apenas a realização de uma pesquisa ação na escola, mas também e, fundamentalmente, o próprio tema desta pesquisa. Como pensar a educação através do corpo em pandemia? A entrevista foi o dispositivo criado para o necessário enfrentamento e posicionamento desta pesquisa. O dispositivo performance é corpo, a crise é do corpo, serve para lembrar que o corpo não somente une os mais diversos pontos de vista sobre performance, bem como está no centro da crise que vivemos. Este artigo é fruto da decantação das entrevistas com professores do ensino emergencial remoto.
\end{abstract}

Palavras-Chave: Performance. Educação. Corpo. Pandemia.

\title{
Performance is Body, the Crisis is of the Body: Interviews with Remote Emergency Education Teachers
}

\begin{abstract}
After a long study on performance approach in education, the pandemic calls into question not only the action research at school, but also and, fundamentally, the research's theme. How to think about education through the body in pandemic times? The interview was the device created for the necessary research confrontation and positioning. The device performance is body the crisis is of the body serves to remind that the body not only unites the most diverse performance's points of view, but is also at the center of the crisis we are experiencing. This article is the interviews with remote emergency education teachers result decanting.
\end{abstract}

Keywords: Performance. Education. Body. Pandemic.

\footnotetext{
${ }^{1}$ Revisão ortográfica e gramatical do artigo realizada por Regina M. C. Vale. Dra. Medicina pela Universidade Federal de Minas Gerais (UFMG). Pesquisadora e escritora.

${ }^{2}$ Doutoranda em Artes pela Universidade Federal de Minas Gerais (UFMG). Mestrado em Artes Cênicas pela Universidade Federal de Ouro Preto (UFOP). Bacharelado e Licenciatura em Dança - Universidade Federal de Viçosa. estelavalevil@gmail.com

(9) http://lattes.cnpq.br/0353520025801738

https://orcid.org/0000-0002-2299-1648
} 


\section{Performance es Cuerpo, la Crisis es del Cuerpo: \\ Entrevistas con maestros de educación de emergencia remota}

\section{Resumen}

Luego de un largo estudio sobre el enfoque de la performance en educación, la pandemia pone en tela de juicio, no solo la realización de investigación acción en la escuela, sino también y, fundamentalmente, el tema de esta investigación. ¿Cómo pensar en la educación através del cuerpo en una pandemia? La entrevista fue el dispositivo creado para el necesario enfrentamiento y posicionamiento de esta investigación. El dispositivo performance es cuerpo, la crisis es del cuerpo, sierve para recordar que el cuerpo no solo une los más diversos puntos de vista sobre la performance, sino que también está en el centro de la crisis que estamos viviendo. Este artículo es el resultado de decantar entrevistas con profesores de educación de emergencia remota.

Palabras clave: Performance. Educación. Cuerpo. Pandemia. 
Depois de um longo estudo sobre a abordagem da performance na educação, a pandemia coloca em questão não apenas a realização de uma pesquisa ação na escola, mas também e, fundamentalmente, o próprio tema desta pesquisa. Como repensar a educação através do corpo em pandemia? A conversa ou a entrevista foi o dispositivo criado para o necessário enfrentamento e posicionamento desta pesquisa em tempos pandêmicos. É o resultado de todo o processo de conflito. Desde o bloqueio à negação e à inércia, até a criação do primeiro dispositivo reflexivo: a noção performance é corpo, a crise é do corpo.

Performance é corpo trata-se de um constructo conceitual que destaca a centralidade do corpo na performance e, consequentemente, na educação como performance. A crise é do corpo também serve para enfatizar que o corpo ocupa o centro da crise contemporânea que se radicaliza com a pandemia. Este exercício reflexivo serve a uma compreensão mais abrangente e necessária da abordagem da performance na educação, lembrando que o corpo não somente une os mais diversos pontos de vista sobre performance, bem como está no centro da crise que vivemos.

Tratar deste dispositivo reflexivo ou constructo conceitual implica em trazer para a discussão todo o denso estudo teórico realizado por esta pesquisa, o que de fato geraria outro artigo. Como o recorte apresentado é a entrevista, neste artigo arriscarei uma síntese. Penso que o maior risco seja simplificar e superficializar algo que é extremamente complexo e profundo, por outro lado sendo a entrevista o resultado deste percurso teórico não posso deixar de trazer esses estudos, mesmo que de forma pontual. Nesta pesquisa, "Corpo" e "Performance" são tratados como categorias do pensamento, nisso implica um vasto e multifacetado universo de estudos.

O que é o corpo? O corpo é uma categoria difícil de apreender, tamanha sua complexidade e centralidade em questões basilares no Ocidente. Como argumentou David Le Breton em seu Adeus ao Corpo (2003), as questões do corpo estão relacionadas ao dualismo, à filosofia mecanicista, ciência moderna e à ciência contemporânea, que levará o corpo máquina a outro patamar. A noção do corpo como exemplo de perfeição para a máquina dá lugar à ideia de que a tecnologia salvará o corpo de sua intrínseca vulnerabilidade com o advento da 
genética, da robótica, da informática e, finalmente, da inteligência artificial.

Para esta pesquisa interessada nas relações entre corpo, performance, educação e pandemia a conversa teórica partiu das perspectivas de Le Breton e da filosofia da mente de Searle (2004), que problematiza as questões deixadas por

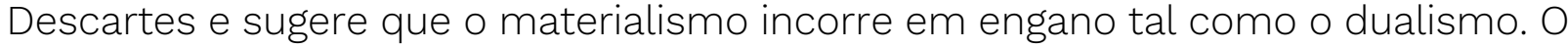
corpo objeto dual é o mesmo corpo objeto materialista. Suas reflexões sobre a mente conversam com os estudos do corpo de Le Breton (2003) que também faz uma revisão histórica, considerando como o corpo vem sendo tratado desde o dualismo cartesiano ao materialismo contemporâneo.

A partir desses estudos o percurso se torna um mergulho no que chamei de espiral filosófica do corpo. A espiral parte de Espinosa que, em contraponto a Descartes, sugere que Deus é Natureza. O corpo como experiência em Espinosa ecoa no pensamento de Nietzsche que o entende como a fonte imanente de toda vida. Também reverbera no corpo sem órgãos e como rede de pulsões de Artaud.

Igualmente está presente na fenomenologia da percepção que demarca uma mudança paradigmática. Para Merleau-Ponty o corpo deixa de ser um mero objeto e, reverberando Espinosa, torna-se mediador de toda experiência. Por sua vez, o pós-estruturalismo faz emergir o corpo acefálico e vital de Derrida; as máquinas orgânicas e máquinas desejantes de Deleuze-Guattari e a materialidade do discurso como acontecimento, a biopolítica e o biopoder pensado por Foucault.

De acordo com Christine Greiner (2005), a metáfora do corpo-orgânico vai dando lugar a novas metáforas do corpo como rede de forças, pulsões e estados corporais. O corpo começa a ser entendido como construção das estruturas de poder e discursos do corpo. O corpo passa de produto dado (imutável) a processo em constante transformação (devir), mudando de estado conforme a ação. Desta forma, Greiner aponta que o corpo passa a ser entendido de forma mais sistêmica e não como produto final, acabado (Greiner, 2005).

Essas transformações no entendimento do corpo estão relacionadas à filosofia pós-estruturalista, mas também fazem parte de um movimento filosófico mais abrangente. Em busca de uma síntese chamei de espiral filosófica do corpo o movimento em oposição a Descartes, que parte de Espinosa atravessando 
Nietzsche e Artaud, a fenomenologia, o pós-estruturalismo até a contemporaneidade. Para Greiner, as fronteiras se dissolvem numa cultura em ação, como um novo órgão, um novo corpo social, onde não se distingue civilização de cultura, cultura de arte, arte de vida. Essa dissolução de fronteiras também tem recebido o nome de performance.

O que é performance? Como o corpo, também uma abrangência e uma complexidade difícil de apreender, "um terreno de tensões epistemológicas, uma vez que não se pode definir o que é performance mas apenas elencar suas camadas de significação" (Villegas, 2020). Como abordagem ao conhecimento, destacam-se três eixos de relevância histórica: a virada linguística; a virada performativa e arte da performance. Estas denominadas viradas dão novos rumos às formas de compreender a linguagem e o comportamento enfatizando o corpo como fonte de ação e significação do mundo.

A virada linguística se dá a partir da filosofia da linguagem com a noção de performativo de John Lang Austin (1962), que inaugurou um novo olhar: a linguagem como ação. Nas ciências sociais e antropologia, a virada performativa se deu através da noção de performance como cotidiano de Erving Goffman (1956) e a noção de "drama social" (1957) de Victor Turner. Estes estudos chamam atenção para a existência dos papéis sociais, da atuação dos atores sociais e da centralidade dos dramas sociais nos processos históricos.

A arte completa a tríade da performance como abordagem ao conhecimento com o advento da Arte da Performance, expressão artística da década de 1970, mas cuja envergadura trouxe a necessidade de uma revisão histórica da arte através da performance. Esforço esse empreendido por Rose Lee Goldberg (1979), partindo das vanguardas artísticas do início do século XX e do Pós Segunda Guerra Mundial. Sua perspectiva ganha continuidade com o trabalho de Jorge Glusberg (2008) e, no Brasil, Renato Cohen (2013). Como manifestação artística a performance caracteriza-se pela ruptura, pelo hibridismo, pela centralidade do corpo na ação e no tempo real.

O contexto maior da performance nasce e se inspira nesta pesquisa através do pensamento de um grande teórico da performance, o professor e diretor norte- 
americano Richard Schechner. Considero-me schechneriana por ter tido a oportunidade de estudar o desenvolvimento da sua Teoria da Performance através da revisão de parte significativa da sua obra. Desde a década de 1960, Schechner vem tratando a performance como uma categoria inclusiva, onde a performance não é alguma coisa que se possa definir e só existe através das relações e interações que se estabelecem a todo instante. A performance não "é", a performance está "entre" as coisas. Esse "como se" é de especial importância, pois indica que a performance pode ser entendida como um tipo de "abordagem ao comportamento" (Schechner, 2002).

O corpo engloba todas as perspectivas de performatividade. A ação acontece no corpo e através do corpo; quem entra em movimento e está em permanente circulação é o corpo; o acontecimento é o corpo em relação a outros corpos (seja de outra pessoa, seja uma árvore, seja um livro); a linguagem (seja falada ou escrita) se dá através do corpo; o discurso e o enunciado são ações materializadas. Quem está sendo produzido é o corpo, antes mesmo da ideia de uma subjetivação do corpo. O corpo é anterior e está além, não tem começo nem fim.

Diversos pesquisadores chamam atenção para o ponto de convergência que o corpo representa para a performance. John Dawsey considera a performance uma mudança paradigmática, que converge as análises para "o modo como os sentidos do corpo são mobilizados na significação do mundo” (Dawsey, 2011). Gilberto Icle argumenta que a performance "encontra ainda no corpo e nas diferentes noções de corpo o campo propício para o seu desenvolvimento" (Icle, 2010). Para Marcelo de Andrade Pereira "seja qual for o contexto de investigação da performance pode-se dizer que, em todos eles, a performance encontra termo e relação no corpo" (Pereira, 2012).

Não apenas a performance encontra termo no corpo, como a performance encontra nos estudos do corpo um campo fértil para o seu desenvolvimento. 0 surgimento de um campo de estudos da performance e educação é exemplo notório do potencial da performance como um novo paradigma centrado no corpo.

Se o corpo é construído, a escola engloba grande e importante parte desse processo de construção, ou como sugeriu Ball de "fabricação dos corpos" (Ball, 
2010). Foucault demonstrou que como toda instituição de confinamento, o lema da escola é vigiar e punir para produzir esse corpo dócil aos grandes interesses financeiros. Na educação, em especial, o corpo se apresenta como a grande questão e a grande contribuição trazida pelo paradigma da performance como apontou Elyse Lamm Pineau. É através do corpo que também se constrói uma educação como performance.

No contexto norte-americano emerge um novo campo de estudos que Pineau sugere chamar de "Pedagogia Crítica Performativa"3 (Pineau, 2002; 2010). A teórica parte dos estudos de Paulo Freire, o grande educador brasileiro, cujas ideias impulsionaram a formação de vários campos reflexivos na educação como a pedagogia crítica norte-americana. A partir da pedagogia libertadora, da noção da escola como local de rituais performativos, de Peter MacLaren, e da performance como paradigma do etnógrafo Dwight Conquergood, Pineau sugere que a potência da performance na educação reside no fato de colocar "o corpo no centro do processo de ensino aprendizagem" e "como ponto de partida conceitual para a educação" (Pineau, 2010).

O repertório da pedagogia crítica performativa inclui além da etnografia e observação participante, metodologias auto etnográficas, painéis e escritas performativas, processos artísticos como produção de conhecimento, exercício da crítica, posicionamento e engajamento. Penso que além de colocar o corpo no centro do processo de ensinoaprendizagem, também seja contribuição da performance colocar a prática artística junto ao corpo no cerne pedagógico. Aliado ao corpo a prática artística toma o centro do processo de ensino-aprendizagem dissolvendo as fronteiras entre o fazer e o saber (Villegas, 2020, p.222).

A partir de todos esses estudos seria realizada uma pesquisa ação na escola, entretanto, com o advento da pandemia foi posta em questão não somente a realização da pesquisa ação, mas também e, fundamentalmente, o próprio tema desta pesquisa. Como pensar a educação através do corpo em tempos pandêmicos?

Dentre as perspectivas filosóficas sobre a pandemia, Franco "Bifo" Berardi

${ }^{3}$ Em inglês "Critical Performative Pedagogy". Algumas traduções sugerem "Pedagogia Crítico-Performativa", outra possibilidade seria "Pedagogia Performativa Crítica", escolhi uma terceira opção "Pedagogia Crítica Performativa" devido a existência de uma "Pedagogia Crítica" norte-americana. 
traz o corpo para o centro da discussão ao argumentar que: "Pela primeira vez, a crise não provém de fatores financeiros e nem sequer de fatores estritamente econômicos, do jogo da oferta e da demanda. A crise provém do corpo" (Berardi, 2020). As questões do corpo imperam. O corpo escancara sua fragilidade, efemeridade, transitoriedade e envelhecimento. Mas também sua necessidade de toque, afeto, presença, calor. Não apenas o medo da morte, mas também o medo da solidão, do desamparo, da fome e do frio estão aguçados e crescentes num mundo pandemizado (Berardi, 2020). Nunca foi tão importante olhar para o corpo, sua fisicalidade, seu emocional, seu mental e ampará-lo. O vírus chegou e encontrou um corpo fragilizado, estressado, sobrecarregado, já desejoso em desacelerar (Berardi, 2020).

Não obstante a riqueza teórica trazida pelo corpo e com ele o enriquecimento do entendimento sobre performance e da abordagem da performance na educação, o constructo performance é corpo e a crise é do corpo, não foi suficiente para aplacar a fome de campo desta pesquisa. Não fazer a pesquisa ação implicava na ausência do contato/ interação/ improvisação com outros corpos. Implicava na ausência das cores e vibrações dos corpos e no precioso registro. O que mostrar, o que oferecer ao olhar, isso é corpo. Era para mim insuportável conformar com uma pesquisa puramente teórica, uma pesquisa que trata, justamente, de corpo, performance e educação em pandemia.

Também preocupado com a perda da potência da prática, o meu orientador Marcos Hill sugeriu que fizesse o exercício reflexivo de pensar a prática no campo do ideal. Como imaginar a ação na escola antes e depois da pandemia? Primeiramente, como imaginar uma ação? Professores podem chegar a traçar planos muito precisos de suas ações, mas tudo pode acontecer no espaço energizado da escola. Também e, fundamentalmente, ansiava não apenas propor práticas de performance na escola, mas principalmente, conversar com as pessoas e propor debates em torno da minha questão de pesquisa: Como repensar a educação através do corpo?

Este dispositivo de pensar a ação no campo do ideal desencadeou outro processo, a criação de um jogo reflexivo sobre três cenários educacionais hipotéticos. Em meio ao mergulho abissal de incerteza e insegurança posto pela 
situação pandêmica, foram pensados três cenários hipotéticos: Num primeiro cenário ficcional o ensino remoto deixa de ser emergencial e se torna a principal forma de ensino institucionalizada. O segundo cenário considera que ocorre o retorno presencial com protocolo de segurança e este se torna o modelo de ensino normatizado. O terceiro cenário propõe a recuperação da normalidade a médio ou longo prazo.

Como pensar a minha prática docente nestes cenários hipotéticos se eu não estou dando aulas? Surgiu, então, a necessidade de conversar com essas pessoas que estão na linha de frente do ensino em tempos de pandemia. Com a realização das entrevistas todos os dispositivos criados se efetivaram. Este artigo é fruto da decantação de doze entrevistas com professores do ensino emergencial remoto. A entrevista vem coroar os esforços teóricos e reflexivos com o que a realidade virtual tem de mais potente no momento, conversar por áudio e vídeo.

\section{Educação em Pandemia}

A literatura sobre educação e pandemia, evidentemente, ainda está sendo construída. Alguns trabalhos buscam uma visão otimista de regeneração e transformação, seja pela dor que nos mobiliza a mudanças como em Hermann (2020), ou na tomada de consciência da vulnerabilidade do corpo na visão de Alfredo Marcos (2020). Frente a todas as incertezas, Marcos repudia o fenômeno de predição que se tornou a filosofia contemporânea em pandemia, acreditando na possibilidade de regeneração das virtudes humanas.

Outros estudos buscam escancarar o bolsonarismo como uma estratégia de necropolítica (Duarte; César, 2020) e trazem dados alarmantes do diagnóstico da educação brasileira em pandemia, desde o despreparo dos professores para lidar com o ensino remoto à fome que assola as crianças sem merenda (Cury, 2020). Para Cury, "o impacto foi a invasão da escola na casa, ou melhor, das escolas nas casas" (Cury, 2020).

Uma casa já invadida pelo trabalho e por um novo protocolo de segurança. Ainda tem espaço para as pessoas? Para o repouso? O contexto ímpar que 
vivemos é de tal extrema complexidade, exatamente, por borrar fronteiras até então muito precisas. Veiga-Neto sugere chamar tal complexidade de "sindemia covídica" (Veiga-Neto, 2020). Sindemia indica que no mundo contemporâneo altamente tecnológico uma pandemia ocasiona efeitos colaterais tão grandes ou maiores do que aqueles causados pelo vírus em si. Um mergulho no caos.

Estes estudos panorâmicos sem dúvida importantes são, entretanto, pouco propositivos. Algumas pesquisas têm buscado nos relatos dos atores escolares pistas para suas investigações. Carvalho (2020) parte da narrativa da experiência escolar de um adolescente, cuja crítica sobre a:

[...] ausência de significado das atividades que lhe haviam sido propostas [...] pode ser interpretada como uma interrogação que condensa a perplexidade de toda uma geração: afinal, em face das condições concretas que vivemos, a experiência escolar ainda tem algum sentido? (Carvalho, 2020, p.8).

Retirado o convívio, a socialização e a afetividade realizadas pela presença física o que resta à educação? Conteúdo? Currículo?

[...] sendo o currículo uma construção social que, de forma direta ou indireta, nos deve envolver a todos. E se os recursos tecnológicos passarem, de forma mais ampla, a fazer parte do quotidiano das escolas, jamais substituirão a relação pedagógica, fundada numa efetiva interação presencial, bem como na partilha e desenvolvimento de valores, atitudes e competências socioemocionais (Morgado; Sousa; Pacheco, 2020, p.8).

Charczuk trabalhou com relatos pessoais de professores, pais e alunos através da metodologia de construção de caso da perspectiva psicanalítica, com o objetivo de pensar o fazer docente no ensino remoto emergencial. A autora problematiza o que chama de "falsa dicotomia" (Charczuk, 2020) entre ensino presencial e remoto, sustentando a argumentação de que o remoto não deve ser considerado inferior ao presencial, pois não é a modalidade de ensino "seja ele presencial ou a distância, ou remoto - que garante à proposta didático-pedagógica o efeito de troca, relação e construção de aprendizagens, mas, sim, os modelos teóricos conceituais que sustentam tais formas" (Charczuk, 2020).

Por seu caráter emergencial o ensino remoto, de acordo com Charczuk, não 
pode ser considerado uma modalidade de ensino, mas sim uma ação pedagógica uma vez que não dispõe de modelos teóricos subjacentes. Efetiva-se na simples transposição das atividades planejadas para o presencial ao contexto virtual. É exatamente por essa razão que ensino à distância (EaD) é diferente do ensino emergencial remoto.

A perspectiva de Charczuk é a de que a eficiência de certo modelo está diretamente relacionada aos modelos teóricos que the sustentam. Evidentemente, a falta de acesso à tecnologia garante a ineficiência tanto do EaD quanto do remoto. Entretanto, Charczuk chama atenção para o fato de que também a escassez de modelos teóricos contribui para esta ineficiência. Desta forma, não seria uma questão da falta da presença física, mas sim da falta de procedimentos adequados e embasados capazes de sustentar o remoto como uma modalidade de ensino. Certamente, a simples transposição de atividades que não foram pensadas para o virtual não apresentará resultado satisfatório. Entretanto, mesmo que tais modelos sejam pensados e aplicados, mesmo que isso resulte na eficiência da modalidade, penso que a grande questão do ensino remoto continua a mesma: Educação fundamental pode ser remota? Mesmo híbrida?

A grande argumentação dos depoimentos tange a falta da presença física que é tão fundamental para o desenvolvimento das crianças e jovens. E com a falta surge a questão: "A experiência escolar ainda tem algum sentido?” (Carvalho, 2020).

Para Türckel (2020) a grande incerteza em tempos pandêmicos recai, justamente, sobre o ensino. A ideia de que a digitalização das escolas já teria nos livrado do problema não leva em consideração que a educação precisa das interações e relações entre corpos. "Os monitores são os principais redutores da educação a dados e informações. [...] é uma medida emergencial que não consegue transmitir muito, sendo ainda bem mais extenuante do que os encontros presencias" (Türckel, 2020).

Em sua conclusão Türckel expõe suas preocupações em relação à ascensão, centralidade, domínio e controle da tecnologia em todos os aspectos da vida póspandemia: 
Os governos sugerem que depois do corona tudo será como antes. É claro. É importante assegurar o pleno restabelecimento de todos os direitos fundamentais. E estar alerta contra a indústria de TI. Ela é a vencedora da crise e vai insistir que seus remédios emergenciais, que superaram a lacuna durante o confinamento, se tornem novos padrões, e que consultas, seminários, psicoterapias, teatro e shows migrem em série para a rede. Furtivamente, fará desaparecer toda uma dimensão da realidade, que todos afirmam ser insubstituivel. A não ser que haja resistência (Türckel, 2020, p.6).

Entendo esta resistência do Türckel como resistência ao esquecimento do corpo e seus afetos, lembrando que o corpo é o centro da vida e dos sentidos que damos ao mundo. Também a penso como resistência à digitalização da escola, porque é através da escola que uma vida digitalizada pode ser normatizada.

\section{Entrevista}

As entrevistas demonstraram que o jogo ou roteiro proposto é potente na medida em que abre espaço para o desabafo e para o exercício da imaginação, desafiando a pensar e sentir em cenários hipotéticos. Foram realizadas até o momento doze entrevistas ${ }^{4}$, cuja primeira decantação da experiência deu origem ao presente artigo. Participaram professores da rede estadual e municipal, professores universitários e também professores do ensino informal (academia de dança e projetos pedagógicos). A minha intenção foi estar completamente aberta para conversar com qualquer instância de ensino que estivesse passando pela experiência do ensino emergencial remoto.

${ }^{4}$ As entrevistas foram gravadas através da plataforma zoom, ocorrendo no intervalo entre a metade do mês de maio e começo de junho de 2021.Todos os participantes autorizaram o uso de vídeo, áudio e depoimento textual para esta pesquisa. 
Tabela 1 - Tabela de participantes da entrevista, indicação de referência, tipo de ensino lecionado, faixa etária dos estudantes, disciplina e localidade. Nomeação dos participantes conforme orientado pelos comitês de ética.

\begin{tabular}{|c|c|c|}
\hline $\begin{array}{l}\text { Forma de citação do } \\
\text { participante } \\
\text { entrevista }\end{array}$ & Tipo de Ensino/ Faixa Etária/ Disciplina & Localidade \\
\hline Professor 1 & Escola Estadual/ Ensino Médio/ Português & $\begin{array}{ll}\text { Belo } & \text { Horizonte } \\
(\mathrm{MG}) & \end{array}$ \\
\hline Professor 2 & $\begin{array}{l}\text { Escola Estadual/ Ensino Fundamental II (11 a } 14 \\
\text { anos) / Arte }\end{array}$ & Ouro Fino (MG) \\
\hline Professor 3 & $\begin{array}{l}\text { Escola Estadual/ Ensino Fundamental II, Ensino } \\
\text { Médio, E.J.A./ História }\end{array}$ & $\begin{array}{l}\text { Santana do Riacho } \\
\text { (MG) }\end{array}$ \\
\hline Professor 4 & $\begin{array}{l}\text { Escola Estadual/ Ensino Integral/Ensino } \\
\text { Fundamental II, Ensino Médio e E.J.A./ } \\
\text { Português }\end{array}$ & Ouro Preto (MG) \\
\hline Professora 5 & $\begin{array}{l}\text { Escola Estadual Ensino Fundamental II, Ensino } \\
\text { Médio e E.J.A/ Arte }\end{array}$ & Teófilo Otoni (MG) \\
\hline Professora 6 & $\begin{array}{l}\text { Escola Estadual Ensino Fundamental II, Ensino } \\
\text { Médio e E.J.A/ Biologia }\end{array}$ & Serro (MG) \\
\hline Professora 7 & $\begin{array}{l}\text { Escola Municipal/ Ensino Fundamental II/ } \\
\text { Ciências }\end{array}$ & $\begin{array}{lr}\text { Ouro } & \text { Preto, zona } \\
\text { rural } & \text { Bandeiras } \\
\text { (MG) } & \end{array}$ \\
\hline Professor 8 & Ensino Universitário/ Física & Natal (RN) \\
\hline Professor 9 & Ensino Universitário/ Performance & $\begin{array}{ll}\text { Belo } & \text { Horizonte } \\
(\mathrm{MG}) & \\
\end{array}$ \\
\hline Professora 10 & Ensino Universitário/ Educação & $\begin{array}{l}\text { Belo Horizonte } \\
\text { (MG) }\end{array}$ \\
\hline Professora 11 & $\begin{array}{l}\text { Ensino Informal Academia de Dança/ Infantil e } \\
\text { Juvenil/ Dança }\end{array}$ & Viçosa (MG) \\
\hline Professora 12 & $\begin{array}{lll}\text { Ensino Informal/ } & \text { Projetos } & \text { Pedagógicos/ } \\
\text { Mediação cultural na escola } & \end{array}$ & Ouro Preto (MG) \\
\hline
\end{tabular}

Essa abertura do leque investigativo também é interessante porque distintos contextos geram diferentes estratégias em torno de um mesmo problema. Por exemplo, no contexto universitário ocorre uma maior adaptação ao ensino remoto, embora a falta de acesso seja uma realidade. Entretanto, no ensino fundamental público não existe adaptação, o que se evidencia é uma total exclusão digital e evasão por consequência da falta de políticas públicas de acesso à tecnologia. Não 
somente isso, o problema do analfabetismo também é central ao acesso desta tecnologia. Por mais distintos que sejam os contextos, a maioria tem que lidar, por exemplo, com o mesmo problema de se dar "aula" para janelinhas pretas numa sala virtual. Os professores não sabem se seus alunos estão, realmente, presentes!

No caso do ensino informal, uma aula de dança por exemplo, esse problema já não ocorre, necessariamente é preciso mostrar o corpo para fazer uma aula de dança. Entretanto, como descreveu a Professora 11, academia de dança: "Você sabe aqueles joguinhos de computador? Pronto, sabe aqueles joguinhos de computador que captam o movimento das pessoas? [...]. A sensação que eu tenho é essa, que os meus alunos são os personagens do joguinho de videogame". Na aula de dança virtual a janelinha preta se transforma no abismo da distância entre os corpos e os limites do que se pode chamar de presença em meio à ausência.

Distintos contextos de ensino estão sendo desafiados a desenvolver estratégias para resolver o problema da ausência dos alunos, no caso do ensino público uma evasão histórica por exclusão digital. Entretanto, por mais que pensemos estratégias que favoreçam a presença e engajamento virtual estudantil (como conversar mais com os alunos), este não é um problema de forma alguma novo. A falta de engajamento não é fruto da pandemia, mas do próprio modelo de educação, cujas velhas e graves falhas tomam proporções abissais em contexto de pandemia.

Por exemplo, com a pandemia todo o ambiente escolar se tornou um risco à vida e toda uma biossegurança está sendo acionada para contornar isso. Entretanto, não é preciso muito esforço para chegarmos à conclusão de que aglomerações enclausuradas em ambientes fechados não podem ser uma coisa saudável. Não é bom para os animais e, certamente, também não é bom para os humanos. Agora uma situação que não era boa se torna inviável devido a pandemia. Penso que higienizar a escola não resolve. O problema das instituições de confinamento é que elas são instituições de confinamento. O cadeião escolar é uma realidade semelhante ao sistema prisional e manicomial. No protocolo de segurança essa semelhança se intensifica com um esquema de segurança muito mais rígido.

Penso que essa higienização da escola vai muito além desse protocolo e que essas salas fechadas para conter aglomerações deveriam ser banidas e a escola 
recriada em espaços abertos de convívio e aprendizagem. Espaços de natureza, saudáveis e propositivos, como os museus de arte contemporânea. O que sempre esteve fora da curva da aprendizagem é o confinamento dos estudantes. O que era um problema se torna insustentável com a pandemia, penso que seja também uma preciosa, talvez única, oportunidade de ruptura com o velho modelo de educação.

O retorno dado pelos participantes depois da longa conversa (algumas entrevistas chegaram a durar quatro horas) foi bastante positiva. Os participantes usaram termos como "terapêutica", "necessária” e "importante”. Gostaram das perguntas e se sentiram instigados a imaginar e a pensar sobre coisas que estão com dificuldade de assimilar e entender. Questões também que para alguns nunca foram pensadas como um problema central na educação - a castração da performance do corpo e a idolatria da abstração do conhecimento como a mais importante forma de aprendizagem.

As respostas dos professores sobre a relevância da entrevista indicaram que "essa conversa é importante", "pensar sobre isso é importante", "é importante pensar sobre isso agora antes que seja tarde". O “importante" se destaca não somente pela relevância do corpo para a educação, mas também pela necessidade fundamental dos professores terem espaços de conversa, de debate e de reflexão.

Eu não conseguia conversar sobre essas coisas, claro que nós professores estamos sempre desabafando, mas nunca paramos pra conversar, realmente debater sobre o que estamos enfrentando e sobre o que estamos prestes a enfrentar (Professor 2, escola estadual).

O que senti nessas falas dos professores é que estão todos precisando, sobretudo, de conversar. Como um processo de saída da negação e confronto com a realidade. Conscientização das sequelas que já existem e preparação para as que, certamente, advirão. Os professores precisam ser ouvidos e também necessitam ouvir a outros e, sobretudo, urge pensar sobre as complexidades do contexto pandêmico que se impõe e se estende por tempo indeterminado.

Como eu me sinto no ensino remoto? Como vou me sentir no presencial com protocolo de segurança? E num eventual retorno à normalidade? Esse é o jogo 
proposto pela entrevista, que culmina no lançamento da minha pergunta de pesquisa aos participantes: Como pensar a educação através do corpo em tempos pandêmicos?

Na entrevista, quando surge a questão do protocolo de segurança sempre destaco que meu interesse não é questionar o protocolo, nem saber se ele será eficiente ou não, mas unicamente pensar como Foucault e Butler sobre as séries de efeitos que esses novos comportamentos produzirão. Certamente está sendo produzido um novo corpo, uma vez que novos comportamentos estão sendo normatizados. Seja de forma temporária ou não, as sequelas já existem e penso que se faz necessário estudar formas de remediação e resistência.

As etapas da entrevista foram descritas como: Desabafo, imaginação, jogo e conclusão. Na primeira parte da entrevista não mencionei a pesquisa e os participantes ficaram à vontade para colocar suas questões na seção do desabafo. Em seguida foram convidados a imaginar como seria a sua aula com protocolo de segurança, uma realidade que está chegando no Brasil. No caso dos participantes desta pesquisa, a maioria não teve experiência com protocolo de segurança até o momento da entrevista (maio e junho de 2021). Na segunda parte da entrevista apresento aos participantes a pesquisa e os convido para jogá-la comigo. Neste artigo trago uma visão geral das etapas da entrevista, uma primeira decantação da experiência, quase também um desabafo.

\section{Desabafo - Ensino Emergencial Remoto}

A primeira pergunta foi na verdade um pedido de desabafo: "Como está sendo sua experiência com o ensino emergencial remoto? O que sentiu? Percebeu? Angústias e preocupações?". A segunda pergunta, "Qual ponto você considera central na sua experiência?", busca apenas retomar o que se destaca no relato. Penso que esse dispositivo de retornar ao ponto central não foi eficiente, houve dificuldade em destacar esse ponto. Alguns participantes entenderam que era para destacar o que foi de positivo na experiência, outros não conseguiram pensar em somente uma questão central. Percebi que a riqueza estava mesmo no desabafo e que as primeiras frases costumam já apontar para a questão central na experiência do participante. 
As respostas dos professores da rede estadual e municipal da educação básica carregam o peso da realidade da exclusão digital dos alunos e também de muitos professores: "Poucos alunos participam. Os alunos estão prejudicados, isso é fato" (Professor 4, escola estadual); "Nós professores estamos sobrecarregados, também e, talvez a sobrecarga seja até maior, para a direção e orientação pedagógica” (Professora 5, escola estadual); “A agonia maior é em termos profissionais [...]. Eu me sinto a pior profissional possível. Ensino remoto não atende nossos alunos. É exaustivo, não chega e não atende. Enganação remota” (Professora 7, escola municipal rural).

Como fechar escolas e instaurar um ensino emergencial remoto sem mínimas políticas públicas de inclusão digital? Sem mínimas políticas públicas de segurança alimentar, social e de saúde? A escola cumpre o papel fundamental de garantir direitos constitucionais fundamentais. Fechar escolas e pôr em funcionamento um tipo de ensino cuja demanda tecnológica é acessível para poucos é mais um crime de um governo acéfalo. É, de fato, "um momento sombrio de total desmonte da educação brasileira" (Professor 3, escola estadual).

Outras respostas dos professores da rede básica enfatizam a dimensão do ser professor em pandemia: "O ensino remoto é uma tristeza. Não tem experiência" (Professor 1, escola estadual), "Minha experiência foi de angústia, solidão e vazio" (Professor 2, escola estadual), "Nada substitui a sala-de-aula" (Professor 3, escola estadual). Não ter experiência ou gerar uma experiência de angústia indica que não é tanto uma questão de avaliar se existe ou não presença no meio virtual, mas sim de que o tipo de presença que se realiza no virtual não satisfaz. O vazio parece traduzir essa sala de vidro repleta de janelinhas, a maioria fechada.

Noutro contexto mais favorável, a dos projetos pedagógicos que atuam em escolas por exemplo, as melhores condições tecnológicas e de acesso à tecnologia não são capazes de amenizar esse sentimento de angústia, "minha sensação é de estar presa no vidro. As pessoas não ligam as câmeras [...]. Não ver o rosto do outro [...]. Rotina cansativa" (Professora 12, projetos pedagógicos). Mesmo quando esta janela deve estar necessariamente aberta, como é o caso de uma academia de dança, a situação é: 
Trágica, distanciamento total. Uma atividade não obrigatória é a primeira a ser descartada. Nós professores do ensino informal estamos passando por um profundo abalo emocional. É extremamente solitário e desanimador. Não tem câmeras fechadas, mas mesmo assim é extremamente solitário (Professora 11, Academia de Dança).

Nestes estudos preliminares foi possível identificar dois perfis de professores: aqueles atormentados com o ensino remoto e aqueles que se sentem confortáveis nele. O conforto pode ser observado com maior intensidade no ensino universitário, onde o ensino a distância é uma realidade e existe um maior acesso à tecnologia. Como apontou o Professor 8, ensino universitário: "Eu batalho há muito tempo por esse tipo de ensino, penso que oferece maior controle do aluno sobre como aprender. Em teoria é fantástico. Pode ser muito bom, só que o problema é a imaturidade dos alunos". Administrar uma sala de aula com uma multidão de 100 alunos é desafiador e o ensino remoto se torna evidentemente melhor.

Entretanto, mesmo o professor universitário com todo o conforto e acesso também está insatisfeito. "O ensino remoto é muito insatisfatório. A docência é feita de interações e relações. Os estudantes não ligam as câmeras, isso me incomoda muito, este ano estou tentando conversar mais [...]. Escola não é a distância, escola é proximidade" (Professora 10, ensino universitário).

Por outro lado, mesmo na rede pública existem professores que se sentem confortáveis no modo remoto e não desejam o retorno das aulas presenciais. Porque se sentem confortáveis com esse tipo de ensino por terem acesso e facilidade, também porque as péssimas condições do ensino público são parcialmente contornadas com o trabalho em casa e, claro, o medo do contágio mesmo com vacinação e protocolo de segurança. É interessante observar que esses professores que se sentem confortáveis com o ensino remoto relataram nesta pesquisa que não gostam da docência, ou do tipo de disciplina que lecionam, ou mesmo do público que trabalham, um público que para eles é inapto e desinteressado.

Por outro lado, os professores que sofrem são aqueles cuja pedagogia sustenta-se no afeto, no envolvimento e no engajamento, seja com os alunos, com suas disciplinas ou com o simples fato de ser professor e estar na escola. O que 
me assusta e preocupa é que estes professores são os que mais sofrem e tendem, inclusive, a desistir de lecionar, alguns professores disseram de forma semelhante que o ensino remoto não é para eles e com protocolo de segurança também é inviável.

\title{
Imaginação - Ensino Presencial com protocolo de Segurança
}

O dispositivo da imaginação foi acionado com a terceira pergunta: "Teve experiência com ensino presencial com protocolo de segurança? Se não, como você imagina este tipo de ensino? ". Apenas uma professora relatou ter tido essa experiência no ensino informal:

\begin{abstract}
Não funciona. Não existe protocolo de segurança pra criança. [...] E as crianças pequenas, crianças de 4 e 5 anos já estão começando a vida social nesse processo pandêmico, elas estão aprendendo o convívio social neste formato, eu acho que elas vão ter dificuldade de aprender a abraçar. [...]. O protocolo para o adolescente não funciona e para a criança pequena me preocupa (Participante 11, Academia de Dança).
\end{abstract}

Como disse Türckel no caso do ensino remoto "quanto menores as crianças, menos produtivo é o processo" (Türckel, 2020). Penso que o mesmo ocorra com o protocolo. Esse protocolo está chegando agora na escola no Brasil e com um ano e meio de pandemia nós já temos uma geração mundial cujos corpos já estão sendo imprimidos com as novas normas sociais. As pessoas já têm um problema a ser considerado: Como ensinar socialização, afetividade, ensinoaprendizagem, ser corpo físico e aprender com o corpo em tempos de pandemia? Talvez seja importante refletir sobre isso agora para que não se corra o risco de ter uma nova geração profundamente prejudicada.

Penso que temos agora uma oportunidade única de fazermos uma reflexão antes de sermos carregados pelo tsunami das circunstâncias. Mesmo dentro do protocolo é possível que não se perca o corpo e seus afetos de vista. É possível conversar sobre isso com os alunos, é possível explorar novas formas de afeto. A troca energética não necessita, necessariamente, do contato físico e mesmo com distância é possível a troca. Se não é possível ver o rosto vamos intensificar o olhar 
e explorar esse tipo de contato.

Mesmo que o protocolo seja potencialmente inibidor do corpo e seus afetos, se existir reflexão sobre isso com as crianças e adolescentes, também entre professores, orientadores e diretores, se houver uma preocupação conjunta, penso que danos maiores podem ser evitados. Entretanto, se a maior preocupação em relação ao protocolo for sua efetiva rigorosidade, talvez seja possível uma geração sem corpo e sem afeto.

O dispositivo da imaginação é acionado quando somos levados a pensar sobre como seria estar em determinada situação. A potência do ato imaginativo se fortalece ao imaginarmos uma situação que estamos prestes a enfrentar e que muito pouco sabemos sobre ela. O interesse aqui não é questionar o protocolo de segurança, nem o ensino com este protocolo, muito menos avaliar sua aplicabilidade ou eficiência. Se vai funcionar ou não, se é um risco à vida ou não, dentre outras questões fogem do escopo. O que se pretende é pensar sobre as séries de efeitos que esses novos comportamentos produzirão. Que tipo de corpo está sendo produzido ou fabricado e como lidar com suas questões?

Os participantes no exercício reflexivo de se imaginarem dando aula no contexto do protocolo relataram: "abafado, amarrado, limitado", "os alunos têm muita necessidade de afeto", "caos”, "vai ser terrível, não vai existir contato, acho inviável", "eu tenho dificuldade até de imaginar", "rompe com alguma coisa", "não é possível", "risco à vida", "não consigo imaginar. Uma vergonha". Nas falas é possível observar que estão todos com muito medo do retorno as aulas, primeiro pelo risco à vida, segundo pelo desconforto do desconhecido, terceiro pela necessidade de inibição do contato. Esse terceiro fator pesa mais para os professores de afeto, enquanto para os professores confortáveis na situação remota pesa mais o medo do contágio.

Algumas falas chamam atenção para a qualidade desse tipo de aula "Conseguiria dar a minha aula, mas perderia a qualidade das aulas, teria que reinventar essa qualidade" (Professor 2, escola estadual). Essa reinvenção da qualidade é de suma importância e onde possivelmente entram as estratégias de desenvolvimento das dimensões que foram limitadas pelo ensino emergencial 
remoto. Por exemplo, não era possível fazer uma roda no remoto, no protocolo não é possível dar as mãos na roda. Então, penso que nós possamos reinventar essa conexão ancestral de dar as mãos na roda, talvez usar um lenço, um fio invisível ou qualquer outra estratégia que possibilite que se faça a roda sem, necessariamente, ter que dar as mãos. O que importa é estar sempre atento e vigilante para não perder de vista o corpo e seus afetos.

No geral, os participantes tiveram dificuldade em imaginar esse ensino com protocolo de segurança. Considerando que esta é uma realidade que estava chegando e para esses professores isso pode ser preocupante. Fiquei surpreendida em como estavam despreparados e desamparados para o enfrentamento desta nova situação pandêmica. Frente à emergência de outro contexto, outros desafios, outras necessidades de adaptação. Penso que seja de extrema urgência e necessidade para além de estudar sobre biossegurança, também avaliar as dimensões educacionais implicadas.

O jogo propôs pensar essas dimensões educacionais a partir de três cenários ficcionais. Estes aspectos foram denominados da seguinte forma: Socialização; Ensino-aprendizagem; Afetividade; Dimensão psicológica/afetiva de quem ensina; Dimensão psicológica/afetiva de quem aprende; Dimensão física do corpo; Performance do Corpo como centro da aprendizagem/ Aprender através do corpo. O exercício foi pensar como ficam cada uma destas dimensões nos diferentes cenários hipotéticos de ensino remoto, presencial com protocolo e normalidade recuperada. Este é o jogo que apresentei aos participantes da entrevista.

\section{Jogo}

O jogo reflexivo se estabeleceu a partir da criação de três cenários educacionais hipotéticos. No jogo, tais cenários ficcionais tornam permanentes suas características, dizia assim para os participantes: "De agora em diante educação para sempre virtual”; "De agora em diante educação para sempre presencial com protocolo de segurança"; "De agora em diante para sempre normalidade recuperada". Foi o jogo do "para sempre". 
O jogo foi criado para um questionário que seria aplicado, onde uma das questões seria uma tempestade de ideias. Para esta pesquisa o questionário não funcionou e me pareceu que nem nas melhores circunstâncias as pessoas querem responder questionários. Eu senti como aplicando a prova na escola. Quando surgiu a ideia da entrevista o questionário se tornou roteiro e o jogo que era uma simples tempestade de ideias passou a ser jogado a dois. O jogo ficou mais complexo, ele se tornou mais jogo.

Além de imaginar os três cenários hipotéticos os jogadores deveriam jogar palavras (mínimo três) sobre cada dimensão da educação considerada: Socialização; Ensino-aprendizagem; Afetividade; Dimensão psicológica/afetiva de quem ensina; Dimensão psicológica/afetiva de quem aprende; Dimensão física do corpo; Performance do Corpo como centro da aprendizagem/ Aprender através do corpo. Todos esses níveis, camadas ou dimensões consideradas são etapas para se pensar a questão da educação através do corpo. Depois de passar por todos os quadrinhos da tabela é que o jogador receberia a pergunta final e conclusiva da entrevista.

O jogo, em especial, consumiu grande parte da entrevista. Sobre o jogo ainda tenho pouco a dizer nesse momento em que ainda não mergulhei nos ciclos de análises das palavras e dos diversos parênteses que emergiram. Fazendo um processo de decantação, fiquei bastante impressionada com a potência do jogo. Todos os participantes levaram o jogo muito a sério. Isso chamou a minha atenção, porque eles poderiam rapidamente ter apenas jogado as palavras sem pensar, inclusive, esse foi o comando. Mas os participantes não conseguiram ou não quiseram simplesmente jogar as palavras e bloqueavam, "não é bloqueio, é o exercício de pensar, a gente quer pensar sobre essas questões" (Professor 2, escola estadual).

Senti em todos os participantes essa seriedade com o jogo e uma necessidade de dar muitos parênteses, algumas vezes com longos relatos. Tudo indica que os participantes gostaram do jogo. O que mais marcou minha observação do jogo foi que frente aos cenários tenebrosos do virtual ou com protocolo por tempo indeterminado, talvez eterno, o retorno à normalidade emerge como um bálsamo a curar feridas. Entretanto, sabemos que todas essas 
questões já eram gritantes, o que a pandemia faz é tornar inviável a aglomeração em espaços fechados. Talvez uma solução realmente eficaz seria abrir esses espaços e construir novas formas de ensino-aprendizagem também livres da grade curricular. Construir para aprender poderia ser muito interessante, o espaço aberto e propositivo também pode abrir as mentes para novas formas de ensino.

O terrível cenário que a pandemia nos impõe também abre espaço para o novo. É um momento oportuno para mudanças. Penso que devemos estar atentos para que essas mudanças favoreçam uma transformação positiva para a educação, não vejo como o aumento da rigidez disciplinar, do controle e da vigilância podem ajudar a escola. Ao contrário, penso que deveríamos quebrar as paredes das salas-de-aula, plantar árvores e fazer hortas nas escolas, trabalhar em espaços abertos e propositivos. Uma escola sem confinamento, sem aglomeração, realizada em espaços saudáveis e de convivência harmoniosa.

\section{"Agora vou jogar minha pergunta de pesquisa para você"}

Finalizado o jogo todos estavam exaustos da tempestade e com alívio chegava a última e derradeira pergunta. Na verdade, toda a entrevista é uma preparação para este momento, o que gera um friozinho bom na barriga. Fazendo uma primeira reflexão sobre as respostas desta pergunta final, a minha intenção preliminar era de que o jogo criasse espaços de reflexão para que se chegasse nessa discussão final. Isso de fato ocorreu, mas percebi que as respostas dos professores ou o emaranhado dos seus pensamentos constituem o próprio jogo. Entendi que somente uma análise do jogo pode, de fato, costurar as reflexões dos participantes.

Este é um labor em processo, o que apresento neste artigo são apenas minhas primeiras impressões, interações e relações com as entrevistas, uma decantação. Dois professores não consideram que pensar a educação através do corpo em pandemia seja possível. O Professor 3, escola estadual, declarou que:

Eu acho que não é possível, me desculpe [...]. Não vejo como possível, não vejo como viável, não vejo como possibilidade. Não é viável em 
contexto de pandemia, assim como muitas coisas não são viáveis na educação em contexto de pandemia, algumas questões têm que ser deixadas de lado, principalmente questões de socialização, que pra educação é tão importante. (Professor 3, Escola Estadual).

Para o professor o contexto pandêmico impossibilita pensar a educação através do corpo como impossibilita a socialização e a afetividade que são corpo. O corpo está no centro da crise, ou “a crise provém do corpo" (Berardi, 2020). O corpo está temporariamente impedido, ele deve ser deixado de lado por enquanto. Ao mesmo tempo a pandemia já se entende por mais de um ano e meio e o ensino presencial com protocolo de segurança está sendo implantando em diversos estados brasileiros sob a forma de ensino híbrido, tornando-se uma realidade para esses professores. Por quanto tempo o corpo pode ser deixado de lado? Quais as consequências de seu impedimento? Como se apresentará esse novo corpo produzido por essas séries de efeitos? E como vamos lidar com suas questões?

As pessoas podem passar bastante tempo sem esportes, bares e festas, as pessoas podem conseguir mesmo ficar em confinamento em suas próprias casas, mas ficar sem educação é bastante complexo. Um, dois, três anos de vida escolar é quase uma fase inteira da vida estudantil. Penso que seja nocivo deixar de lado o corpo na educação. Primeiro porque o corpo é a fonte imanente de tudo e, portanto, uma vida sem corpo não é possível. As coisas que não são viáveis em contexto de pandemia não deixam de existir porque vivemos uma pandemia. Socialização, ensino-aprendizagem, afetividade, a pessoa que ensina e a pessoa que aprende, o corpo físico e o aprender com o corpo ainda estão presentes em um mundo em pandemia e devem ser constantemente lembrados.

Outra professora da escola estadual pensa a questão de forma mais ampla, para além da pandemia, não acreditando possível que qualquer coisa possa sanar o modelo educacional vigente:

Pra mim o que pode acarretar grandes mudanças, mudanças profundas, é realmente a queda deste modelo de educação que a gente tem. O grande limitante da performance do corpo é este modelo de educação. Porque é isso, a performance é a potência do corpo que é a potência da pessoa e a escola é onde estão todos os potentes e porque isso não é potencializado? Porque não há desejo. [...] pra mim não vai mudar a escola porque o modelo de escola, esse modelo de educação que é a nossa referência, ele quer exatamente esse resultado e ele está preocupado em 
garantir esse resultado. E pra ele garantir esse resultado não importa se você foi pela performance ou pelo livro, você entrega esse resultado no final do bimestre. O que a escola quer? O que o estado quer? Um papel, um número (Professora 5, Escola Estadual).

Para esta professora a grande provocação da performance não seria pensar a educação através do corpo, mas sim que a realização da educação como corpo só é possível através da ruptura com o próprio modelo de educação. Este modelo é regido pela performatividade contemporânea, preocupada com o desempenho e o resultado em estatísticas. A escola é parte integrante e fundamental desse "sistema de terror" implantando ao "fabricar" o corpo escolarizado (Ball, 2010).

Esse modelo que nos escolarizou é o único que conhecemos. A Professora 10, ensino universitário, explicita bem este ponto ao dizer que nem sabe como seria isso de pensar a educação através do corpo, porque ela não teve formação nem experiência pra isso. Para a professora talvez isso seria possível com cursos de formação e projetos na escola. Entretanto, mesmo a melhor formação e os melhores projetos não parecem suficientes, somente uma ruptura com a castração do corpo poderia permitir o desenvolvimento da performance do corpo.

Passam os gênios da educação e, absurdamente, a sala-de-aula permanece no mesmo formato. Penso que transformações profundas são realizadas em tempos de exceção como o que enfrentamos. O que vai definir se tais mudanças serão para melhor ou para pior será o nível de reflexão, resistência e enfrentamento. O modelo instaurado tende a permanecer instaurado, como os alunos em inércia em suas carteiras enfileiradas tendem a permanecer em inércia. As transformações tendem é para o aumento da vigilância e controle sobre as pessoas, na escola não vai ser diferente, muito pelo contrário, a escola vai garantir, justamente, que isso aconteça.

Entretanto, ainda podemos abrir e insuflar possibilidades de ruptura. Sempre será possível mesmo em pandemia e talvez, transformações inesperadas sejam mais possíveis em tempos de caos civilizatório. O mesmo estado pandêmico que limita e sufoca o que já era difícil, pode levar a transformações quase impossíveis, como quebrar as paredes da sala de aula. Esse espaço que permanece no mesmo formato ultrapassado tem a oportunidade de ser repensado. A questão do espaço escolar como um problema central na educação encontra-se no depoimento da 
Professora 12 que leciona em projetos pedagógicos na escola:

É, eu acho que um grande problema do espaço escolar é que ele é muito enrijecido e extremamente disciplinado. Então eu tenho a impressão de que as escolas remetam um pouco à questão da cadeia mesmo, né? Parece que as salas são celas. Isso é duro de falar, mas infelizmente... E o professor é o carcereiro, porque na medida em que você tem que deixar o aluno ir no banheiro ou não, pelo amor de Deus, né? Você entende que você é um carcereiro, [...]. Você professor não pode usar uma roupa tal porque você está dando aula pra adolescente. Você não pode usar uma calça justa ou um decote porque enfim... Porquê? Isso é só um corpo, é um corpo como outros corpos (Professora 12, Projetos Pedagógicos em Escolas.

O “cadeião" é a realidade da instituição de confinamento que é o modelo institucionalizado de educação descrito por Foucault como um sistema de vigilância e punição como o manicômio e a prisão. Por se tratarem de aglomerações de pessoas em locais fechados a saúde nem física, nem emocional ou mental jamais foi favorecida. Em tempos pandêmicos a escola se torna um risco à vida, mas a higienização da escola vai muito além do melhor protocolo de segurança. A escola precisa ser repensada em espaços abertos, somente a ruptura com o sistema de confinamento pode realmente tornar a escola saudável e segura. Com ar, com árvores, com terra, com espaços propositivos para que o corpo e seus afetos não sejam esquecidos e possam ser potencializados.

Não somente os espaços, mas as formas de ensino também devem ser repensadas. O ensino remoto, ao que parece, veio pra ficar e tem tomado a forma de ensino híbrido, um ensino tanto presencial quanto remoto, como na educação à distância. O Professor 3, escola estadual, enfatizou em sua resposta as questões do ensino remoto:

Estamos corpo, estamos corpo através dessas telas. Quando você trabalha com o corpo, eu penso comigo nessa trajetória de sala de aula que o corpo precisa estar presente, dai a gente vai entrar na discussão do quê que é presença. Eu estou falando da presença física, eu estou falando do professor em sala de aula, é desta presença que estou falando. Não essa presença tela que nós estamos, porque nessa presença os nossos corpos estão sendo mediados por essa tela, por essa tecnologia que faz a gente estar aqui agora, mas eu não te sinto (Professor 3, Escola Estadual). 
Este "corpo-tela" se aproxima do pensamento de Le Breton, que entende existência virtual como "sem corpo", "sem rosto" e "sem toque" (Breton, 1999). "Eu não te sinto" porque um mundo sem corpo é um mundo sem afetos e sem sujeitos, o que Le Breton chama de "extremo contemporâneo", caracterizado pelo "controle absoluto e pelo narcisismo furioso" (Breton, 1999). Para ele, a partir da dissociação entre corpo e experiência, viabilizada pela realidade virtual ao proporcionar "sentir fisicamente um mundo sem carne" (Breton, 1999), a relação com o mundo transforma-se em relação com dados.

Com a pandemia a imersão no mundo virtual toma proporções assustadoras, ela se radicaliza e se torna a única forma de contato possível num contexto pandêmico. Essa experiência nos oferece uma oportunidade de sentir como seria um mundo-tela. Nele, a performance não é mais corporal, mas sim da mediação tecnológica do corpo.

\section{Considerações Finais}

Frente à implacabilidade dos cenários remoto e com protocolo, a antiga realidade recuperada parece um paraíso perdido, um sonho idílico, quase uma utopia. Mas longe da perfeição a realidade que conhecemos é dura e cruel, nela a escola é o "cadeião". Quando consideramos os aspectos de socialização, ensinoaprendizagem, afetividade, a pessoa que ensina, a pessoa que aprende, corpo físico e aprender com o corpo, todas essas camadas ou dimensões se reduzem, se limitam, se atrofiam e algumas podem até mesmo desaparecer em tempos pandêmicos. O retorno à normalidade se torna o ideal perdido.

Entretanto, os novos problemas não são tão novos assim, nós escolarizamos e fomos escolarizados por um modelo de ensino arcaico e massacrante que não se altera. Passam os gênios da educação e a educação continua infinitamente chata, porque chata é a abstração do conhecimento. Não obstante sua aclamada utilidade e universalidade, abstrair as coisas para conhecê-las é apenas uma das incontáveis possibilidades de se aprender, inclusive nas formas remotas e com protocolo de segurança.

Instituições de confinamento podem ser necessárias para presos e doentes, 
mas jamais serão ambientes saudáveis e, certamente, são inaceitáveis para crianças e jovens. Se nem uma educação libertária livrou a educação desse modelo, não é a performance que o conseguirá. Mas penso que a performance pode provocar a educação de tal forma que possamos sim abrir e criar novos espaços para uma educação através do corpo. O corpo não deve ser menosprezado, na verdade ele é o verdadeiro centro do modelo educacional (todo baseado na castração do corpo) e da crise que vivemos (isolamento e distanciamento do corpo).

Antes que a criança pandemizada se torne um adulto pandemizado ainda existe tempo para conversar com ela. O que mais precisamos nesse momento é conversar. Ainda é possível dizer a esta criança que não devemos temer as outras pessoas e que também não devemos temer a natureza. Que nós estamos vivendo um momento anormal de distanciamento, mas que isso está nos fazendo repensar muitas coisas. Como viver em harmonia em espaços saudáveis, espaços de natureza. É preciso dizer para esta criança que o mundo está repleto de microrganismos que vivem em harmonia na terra, no ar que respiramos, em nossa pele, dentro do corpo e que não podemos viver sem eles, assim como a natureza precisa deles para estar em equilíbrio. Nós também precisamos das outras pessoas para viver em equilíbrio porque somos seres sociais.

A tecnologia pode ser boa para a criança, mas nunca como o centro da vida, pois a fonte imanente da vida é o corpo e seus afetos. A criança precisa brincar com outras crianças e explorar o mundo para se desenvolver e crescer saudável. Ela precisa de espaços abertos, interativos e propositivos para se relacionar e aprender a ser com o outro. Espaços para aprender a sentir a si mesma e a sentir ao outro, para aprender a negociar regras e conviver em sociedade. Também precisa estar em contato com a terra, respirar ar puro, beber água limpa e se nutrir de alimentos saudáveis para ter o seu sistema imunológico desenvolvido e fortalecido. Crianças saudáveis vivem em ambientes saudáveis, espaços saudáveis jamais serão as salas-de-aula radicalmente higienizadas, espaços saudáveis são espaços de natureza. Tudo isso também vale para os adultos.

Por fim, retorno à questão: Educação fundamental pode ser remota? Mesmo híbrida? Não é de se espantar que as atividades presenciais estão conseguindo ser 
transpostas para o virtual com tanta facilidade. A abstração do conhecimento já é por si só uma relação com dados codificados e não com as coisas do mundo real. No remoto ou à distância essa relação apenas se intensifica e alcança um clímax. O que salva a escola da exaustiva chatice em se abstrair as coisas para poder conhecê-las é o que a escola tem de real, sua materialidade: o convívio dos corpos.

Performance é corpo e a crise é do corpo. Podemos nos conformar com a inevitabilidade do aumento do controle, tornando abissais as conhecidas falhas no modelo de educação, ou podemos resistir através do potencial anárquico latente em toda crise. Em pandemia, o confinamento escolar que nunca foi saudável se torna inaceitável, que isso sirva para a necessária transformação da escola, rompendo com as estruturas enrijecidas da sala de aula. É possível outras formas de ensino-aprendizagem centradas no corpo e ensinar em espaços abertos, de convivência, de interação e de proposição.

Como denunciou Türckel (2020), toda uma dimensão da realidade pode desaparecer se não houver resistência. Estaremos na eminência da digitalização da escola e de todos os setores da vida? É possível resistir? É possível não permitir que o corpo e seus afetos sejam esquecidos? O dilema da educação é central para a aderência ou resistência a uma vida completamente digitalizada, na qual a pandemia que vivemos nos proporciona experimentar. Se a escola normatizar a vida digitalizada, possivelmente, veremos emergir uma nova geração que desconhecerá valores que hoje são imprescindíveis.

\section{Referências}

BALL, Stephen J. Performatividades e Fabricações na Economia Educacional: rumo a uma sociedade performativa. Educação \& Realidade, 35(2): 37-55, 2010. Disponível em: https://seer.ufrgs.br/educacaoerealidade. Acesso em: 12 mai. 2021.

BERARDI, Franco "Bifo". Crónica de la psicodeflación. Editorial ASPO (Aislamiento Social Preventivo y Obligatorio), 35-54., 2020. Disponível em: http://iips.usac.edu.gt/wp-content/uploads/2020/03/Sopa-de-Wuhan-ASPO.pdf. Acesso em: out. 2020.

CARVALHO, José Sérgio Fonseca de. Um Sentido para a Experiência Escolar em Tempos de Pandemia. Educação \& Realidade, Porto Alegre, v. 45, n. 4, p.1-13, 2020. 
Disponível em:

https://seer.ufrgs.br/educacaoerealidade/issue/view/4228/showToc. Acesso em: 10 jun. 2021.

CHARCZUK, Simone Bicca. Sustentar a Transferência no Ensino Remoto: docência em tempos de pandemia. Educação \& Realidade, Porto Alegre, v. 45, n. 4, p.1-20, 2020. Disponível em:

https://seer.ufrgs.br/educacaoerealidade/issue/view/4228/showToc. Acesso em: 10 jun. 2021.

CURY, Carlos Roberto Jamil. Educação escolar e pandemia. Pedagogia em Ação, Belo Horizonte, v.13, n. 1, p.8-16, 2020. Disponível em: https://periodicos.pucminas.br/pedagogiacao/article/view. Acesso em: 10 jun. 2021.

DAWSEY, John Cowart. Schechner, teatro e antropologia. Cadernos de Campo, São Paulo, n. 20, p.3-30, 2011. Disponível em: www.revistas.usp.br/cadernosdecampo/article/view/36806. Acesso em: 09 nov.2020.

DUARTE, André Macedo; CÉSAR, Maria Rita de Assis. Negação da Política e Negacionismo como Política: pandemia e democracia. Educação \& Realidade, Porto Alegre, v. 45, n. 4, p. 1-22, 2020. Disponível em:

https://seer.ufrgs.br/educacaoerealidade/issue/view/4228/showToc. Acesso em: 10 jun. 2021.

GREINER, Christine. Corpo (o): pistas para estudos indisciplinares. São Paulo: Annablume, 2005.

HERMANN, Nadja. A Aprendizagem da Dor. Educação \& Realidade, Porto Alegre, v. 45, n. 4, p.1-12, 2020. Disponível em:

https://seer.ufrgs.br/educacaoerealidade/issue/view/4228/showToc. Acesso em: 10 jun. 2021.

ICLE, Gilberto. Para Apresentar a Performance à Educação. Educação \& Realidade, 35(2): 11-22, 2010. Disponível em: https://seer.ufrgs.br/educacaoerealidade. Acesso em: 12 mai. 2021.

LE BRETON, David. Adeus ao Corpo. Campinas: Papirus, 2003.

MARCOS, Alfredo. Con Covid y Sin Covid: la vulnerabilidad humana. Educação \& Realidade, Porto Alegre, v. 45, n. 4, p.1-12, 2020. Disponível em:

https://seer.ufrgs.br/educacaoerealidade/issue/view/4228/showToc. Acesso em: 10 jun. 2021.

MORGADO, J. C.; SOUSA, J.; PACHECO, J. A. Transformações educativas em tempos de pandemia: do confinamento social ao isolamento curricular. Práxis Educativa, Ponta Grossa, v. 15, p.1-10, 2020. Disponível em: https://www.revistas2.uepg.br/index.php/praxiseducativa. Acesso em: 10 jun. 2021. 
PEREIRA, Marcelo. Performance e Educação: Relações, significados e contextos de investigação. Belo Horizonte, Educação em Revista, v.28, n.01, 289-312, 2012. Disponível em: https://seer.ufrgs.br/educacaoerealidade. Acesso em: 12 mai. 2021.

PINEAU, Elyse Lamm. Critical Performative Pedagogy: Fleshing out the politics of liberation education. In: Nathan Stucky; Cynthia Wimmer (Org.) Teaching Performance Studies. Illinois: Board of Trustees, 2002. 41-53.

PINEAU, Elyse Lamm. Nos Cruzamentos entre a performance e a Pedagogia: uma revisão prospectiva. Universidade Federal do Rio Grande do Sul, Revista Educação e Realidade, 35(2): 89-113, 2010. Disponível em: https://seer.ufrgs.br/educacaoerealidade. Acesso em: 12 mai. 2021.

TÜRCKEl, Christoph. Medo e Razão em Tempos de Coronavírus. Educação \& Realidade, Porto Alegre, v. 45, n. 4, p. 1-7, 2020. Disponível em:

https://seer.ufrgs.br/educacaoerealidade/issue/view/4228/showToc. Acesso em: 10 jun. 2020.

VEIGA-NETO Alfredo. Mais uma Lição: sindemia covídica e educação. Educação \& Realidade, Porto Alegre, v. 45, n. 4, p. 1-20, 2020. Disponível em:

https://seer.ufrgs.br/educacaoerealidade/issue/view/4228/showToc. Acesso em: 10 jun. 2021.

VILLEGAS, Estela V. Reflexões sobre os Estudos da Performance e Teoria do Fluxo na Educação em Contexto de Pandemia. In: MACEDO, Daniela R. Artes [recurso eletrônico]: propostas e acessos. Ponta Grossa, PR: Atena, 2020, 217 -226.

SCHECHNER, Richard. Performance Studies: An Introduction. New York: Routledge, 2002. 